\title{
Does Unilateral Thyroid Cancer Affect The Malignant Risk Of Contralateral Thyroid Nodules?-A Retrospective Cohort Study
}

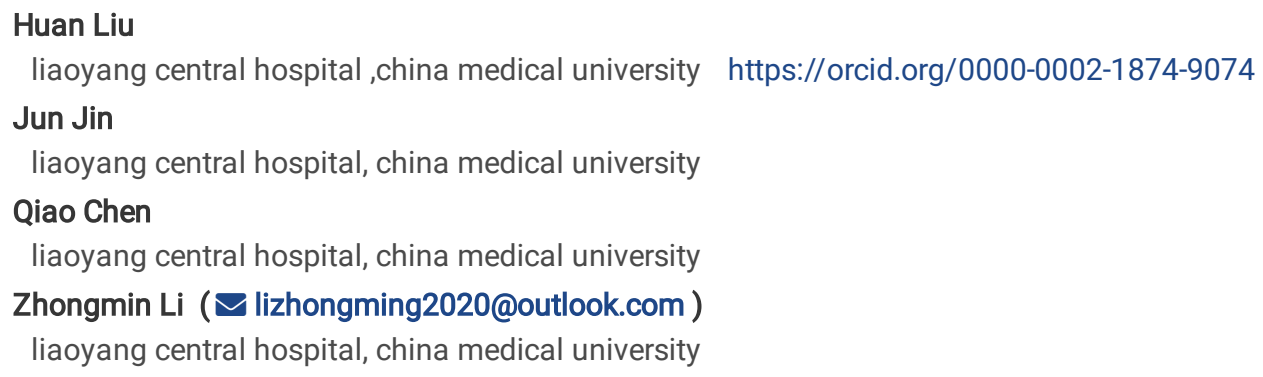

\section{Research}

Keywords: Bilateral thyroid nodules, TI-RADS, Malignant risk, Postoperative complications Surgical procedures

Posted Date: December 2nd, 2020

DOI: https://doi.org/10.21203/rs.3.rs-117736/v1

License: (c) (i) This work is licensed under a Creative Commons Attribution 4.0 International License. Read Full License 


\section{Abstract}

\section{Background}

The incidence of thyroid nodules increased significantly, but the mortality rate of thyroid cancer remained stable or even decreased. However, surgical treatment of thyroid nodules is more aggressive, including the number and scope of surgery. the purpose of our study was to evaluate whether unilateral thyroid nodules affect the malignancy risk of contralateral thyroid nodules.

\section{Methods}

We conducted a retrospective study on all patients with thyroid nodules in a tertiary hospital within one year. Unilateral and bilateral thyroid nodules were the control group and the experimental group, respectively. Based on the TI-RADS grades, the experimental group and the control group were divided into two subgroups. We used chi-square test or Fisher's exact test to evaluate whether there were statistical differences in the incidence and pathological types of thyroid cancer between the experimental group and the control group.

Results

Our study showed that there was no significant difference in malignant risk between the experimental group 1 and the control group 1 , and the experimental group 2 and the control group 2 (20\%vs35\%, $p=0.724,63.16 \% v s 76.32 \%, p=0.297$, respectively). Both the a-side thyroid of the experimental group and the control group were papillary thyroid carcinoma, including micropapillary thyroid carcinoma, and there was no difference in the proportion of micropapillary thyroid carcinoma ( $p=0.200,0.620$, respectively).

Conclusions

There is no evidence that bilateral thyroid nodules affect each other in terms of malignant risk, that is, in bilateral thyroid nodules, unilateral thyroid cancer does not change the malignant risk of contralateral thyroid nodules.

This study has been registered with the Chinese Clinical Trial Registry, clinical trial registration number: ChiCTR2000038611, registration time: 2020-09-26.

\section{Introduction}

Thyroid nodules are defined as discrete lesions within the thyroid gland, radiologically distinct from surrounding thyroid parenchyma (1). Thyroid nodules are extremely common in the general population, and the study reports that it is $4 \%-7 \%$ and $30 \%-67 \%$ of the population by palpation and imaging examinations, respectively (2). At present, due to the popularity and application of high-resolution imaging examinations, we notice that compared with patients with thyroid nodules due to thyroid-related symptoms or thyroid palpation, more and more patients are accidentally discovered by imaging examinations. Most of these accidental thyroid nodules are usually asymptomatic and small (3). Research by Guth S et al. also shows that up to $68 \%$ of the general population have occult thyroid nodules (2). many imaging examinations can identify thyroid nodules. the incidence of thyroid nodules in ultrasound, computed tomography (CT) or magnetic resonance imaging (MRI), 18 fluorodeoxyglucose positron emission tomography (PET) is $65 \%, 15 \%, 1 \%$ to $2 \%$, respectively (4). Among them, ultrasound is the most common imaging examination for the detection of thyroid nodules. Moreover, thyroid ultrasound is recommended by the British, American, and European Thyroid Association (BTA, ATA, and ETA, respectively) as the first-line examination to evaluate thyroid nodules (1.5.6). Thyroid ultrasound can accurately identify malignant thyroid nodules, and may even be better than the pathological results of thyroid fine-needle aspiration biopsy (FNAB) (7.8). Thyroid nodules include benign and malignant ones, and the proportion of malignant thyroid nodules varies from $4 \%$ to $12 \%$, including thyroid nodules accidentally discovered by imaging examinations (7.9-16). Because of the high incidence of thyroid nodules in the population, the number of patients with thyroid cancer is huge. Thyroid cancer currently ranks fifth among female cancers. It is estimated that by 2030, thyroid cancer will rank second and ninth in female and male cancers, respectively (17). Not all thyroid nodules require biopsy or even surgical treatment. More than $90 \%$ of detected thyroid nodules are clinically insignificant because they have no ultrasound features that suggest malignancy or because they are cytologically benign (18). The emergence and application of the Thyroid Imaging Report and Data System (TIRADS) (19), developed by the American College of Radiology (ACR), allows surgeons to stratify the risk of thyroid nodules and adopt appropriate management strategies for thyroid nodules. This has the benefits of timely treatment of clinically significant thyroid cancer, and also reduces the increased costs and risks due to biopsy and treatment of benign thyroid lesions and indolent thyroid cancer. The partial analysis shows that the malignant risk of TR1-5 thyroid nodules is significantly different. The malignant risks of TR1-5 thyroid nodules are $<2 \%,<2 \%, 5 \%, 5 \%-20 \%, \geq$ $20 \%$, respectively.

The incidence of thyroid nodules is increasing, however, the attributable mortality of thyroid cancer remains stable or even decreases. At present, a more aggressive strategy for thyroid nodules is adopted in clinical practice, which is not only reflected in the significant increase in the number of surgery for thyroid nodules but also in the scope of surgery (preferably total thyroidectomy or subtotal thyroidectomy), even if the patient is 
Low-medium risk of thyroid cancer. Because most thyroid cancers are characterized by indolence, these thyroid cancers may not cause any symptoms in the patient's life or have no impact on the lifespan of the patient. Therefore, not all thyroid cancer are required surgery immediately. This more aggressive treatment strategy not only leads to an increase in the number of patients with thyroid postoperative complications but also increases the risk of postoperative complications, especially long-term and serious postoperative complications. Therefore, from the perspective of patients and society, it may not be beneficial. The thyroid is usually characterized by bilateral nodules. According to the anatomical characteristics of the thyroid, the study regarded the bilateral thyroid gland as two separate parts to investigate whether the two affect each other in terms of malignant risk.

\section{Materials And Methods}

\subsection{Study design and population}

This study was a single-center retrospective cohort study. All patients with thyroid nodules were enrolled in the Department of General surgery of a tertiary hospital from December 2018 to December 2019. According to the inclusion criteria and exclusion criteria, the subjects were screened and grouped. Then, statistical analysis was performed on the experimental group and the control group.

\section{2 data collection}

The data of this study were obtained through the hospital electronic case system. The research data included demographic characteristics (including age and gender), chief complaint, medical history, thyroid ultrasound results, surgical procedures, and postoperative pathology. Among them, thyroid ultrasound results included TI-RADS classification of thyroid nodules, thyroid nodule size, and cervical lymph nodes.

\subsection{Research objects and groups}

Excluding patients with incomplete data or other interfering factors, other patients were divided into the experimental group and the control group according to the results of thyroid ultrasound. First of all, to facilitate the subsequent statistical analysis, we had a special definition for bilateral thyroid cancer. For bilateral thyroid cancer, the side with higher TI-RADS grade or more malignant pathology was b-side thyroid, while the contralateral side was a-side thyroid. For example, bilateral thyroid cancer, in which one side was papillary carcinoma (a-side), the other side was undifferentiated carcinoma or medullary carcinoma (b-side).In this study, statistical analysis was performed on the a-side thyroid nodules in the experimental group and the thyroid nodules in the control group.

The inclusion criteria of the experimental group: (1) Bilateral thyroid nodules; (2) Bilateral thyroid nodules were surgically removed; (3) Bilateral

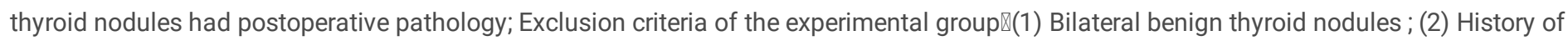
malignant tumors in other tissues or organs (except thyroid); (3) History of thyroid surgery due to thyroid nodules or other thyroid diseases. Those who met the above conditions were the experimental group, which were divided into two subgroups based on the TI-RADS classification of a-side thyroid nodules. TI-RADS 3 and 4 were the experimental groups 1 and 2, respectively. The inclusion criteria of the control group: (1) Unilateral thyroid nodules; (2) Unilateral thyroid nodules were surgically removed; (3) Unilateral thyroid nodules had postoperative pathology; Exclusion criteria of the control group $₫(1)$ History of malignant tumors in other tissues or organs (except thyroid); (2) History of thyroid surgery due to thyroid nodules or other thyroid diseases. Those who met the above conditions were the control group, which were divided into two subgroups based on the TI-RADS classification of unilateral thyroid nodules. TI-RADS 3 and 4 were the control group 1 and 2 , respectively.

\section{4. statistics}

In statistical analysis, we used absolute frequencies and percentages to describe categorical variables, and mean and $95 \%$ confidence intervals to describe continuous variables. Student's t-tests were used to determine the difference in age between the experimental groups and the control groups. In terms of gender, postoperative pathological results, and surgical procedures between the experimental groups and the control groups, we used the chi-square test or Fisher's exact test to determine the difference. All analyses were performed using IBM SPSS Statistics version 25; $\mathrm{p}<0.05$ (bilateral) was statistically significant.

\section{Results}

The collection and grouping process of cases was shown in Fig 1.

Our results on demographic characteristics were shown in Table 1. The average age of the experimental group and the control group were $50.82 \pm 10.98$ and $47.72 \pm 9.58$, respectively $(P=0.093>0.05)$. The average age of the experimental group 1 and the control group 1 were $50.11 \pm 10.244,50.13 \pm 9.848(P=0.993>0.05)$, respectively. The average age of the experimental group 2 and the control group 2 were $53.26 \pm 9.48$ and $46.76 \pm 9.43$, respectively $(P=0.037 \rrbracket 0.05)$. In terms of gender, there were $P=0.680(>0.05)$ and $P=0.016(<0.05)$ in the experimental group 1 and the control group 1, and the experimental group 2 and the control group 2, respectively. 
We used the chi-square test to statistically analyze the postoperative pathological distribution of the two groups. The statistical results were shown in Table 2. We saw that there were no significant differences in the two subgroups, and their $p$-value was $0.724(>0.05)$ and 0.297 ( $>0.05$ ), respectively. In our collection of case data, we saw that thyroid cancer in the a-side thyroid of the experimental group and the control group were thyroid papillary carcinoma (including thyroid micropapillary carcinoma), and there were no other types of thyroid cancer. Moreover, there were no significant differences in the two subgroups, and the P-value was $0.200(>0.05)$ and $0.620(>0.05)$, respectively. Because there were fewer cases in the control group 1, we can not compare the proportion of thyroid micropapillary carcinoma in thyroid papillary carcinoma, but in the experimental group 1, 2, and the control group 2, we saw that the proportion of thyroid micropapillary carcinoma was relatively high. We found that the proportion of thyroid micropapillary carcinoma was relatively high, reaching $61.54 \%$, $83.3 \%$, and $89.66 \%$, respectively. We saw that when the thyroid nodules on the a-side of the experimental group and the control group were benign, the statistical analysis of the surgical procedures of the two subgroups was shown in Table 2.There was no significant statistical difference between the experimental group 1 and the control group 1 ( $p=0.131>0.05)$. However, there were significant statistical differences between the experimental group 2 and the control group $2(p=0.001 \otimes 0.05)$. We saw that when the thyroid nodules in the experimental group and the control group were malignant, the results were shown in Table 3. Although statistical results cannot be obtained in the two subgroups due to the small number of cases, we can still see that more patients in the experimental group and the control group undergo thyroid lobectomy.

We saw the distribution of pathological types of b-side thyroid carcinoma in the experimental group, as shown in Table 4. In the experimental group 1, the pathological types of thyroid carcinoma were $64(98.46 \%)$ thyroid papillary carcinoma, including 31 (47.69\%) thyroid micropapillary carcinoma, and 1 (1.54\%) medullary thyroid carcinoma. Similarly, in the experimental group 2, 18 (94.74\%) thyroid papillary carcinoma, including 7 (36.84\%) thyroid micropapillary carcinoma, 1 (5.26\%) thyroid undifferentiated carcinoma.

\section{Discussion}

Thyroid nodules are an extremely common disease and have a high incidence in the general population. First, we compared the demographic characteristics of the experimental group and the control group. We saw that there was no significant statistical difference in age and gender between the experimental group 1 and the control group 1. However, there were statistical differences in age and gender between the experimental group 2 and the control group 2. We saw that compared with the experimental group 2 , the average age in the control group 2 was younger(46.76vs.53.21 p=0.037) and there were more male patients $(19 / 42 v s .0 / 15 p=0.016)$. This is consistent with the fact that men with thyroid cancer are usually younger.

A systematic review including 14 studies at a moderate risk of bias found the odds ratio for thyroid cancer to be lower in patients with a multinodular goiter than in those with single nodules (20). Moreover, thyroid nodules are usually bilateral nodules. Because of the anatomical characteristics of the thyroid, we regarded the bilateral thyroid gland as two independent units to evaluate whether bilateral thyroid nodules interact with each other in terms of malignant risk. Our study showed that there was no significant difference in malignant risk between the experimental group 1 and the control group 1, and the experimental group 2 and the control group 2 (20\%vs. 35\%, p=0.724, $63.16 \%$ vs. $76.32 \%$, $\mathrm{p}=0.297$, respectively).

Because the types of thyroid carcinoma in the a-side of the experimental group and the control group were all papillary thyroid cancer, including micropapillary thyroid carcinoma, we saw no significant difference in the proportion of micropapillary carcinoma between the two subgroups $(p=0.200, p=0.620$, respectively). Moreover, we also noticed that it was extremely high, especially in the experimental group 2 and the control group 2 , reaching $83.33 \%$ and $89.66 \%$, respectively. We saw that in the b-side of the experimental group, except for 1 medullary thyroid carcinoma in the experimental group 1 and 1 Anaplastic thyroid carcinoma in the experimental group 2, all other cases were thyroid papillary carcinoma.

Although thyroid nodules are prevalent in the general population, more than $90 \%$ of thyroid nodules have no clinical significance, because most of them are benign or even malignant thyroid nodules, especially those smaller than $1 \mathrm{~cm}$, which usually show indolent or non-invasive behavior. Therefore, not all thyroid nodules require surgery(18.21-26). For benign thyroid nodules only need regular ultrasound examination, Surgery may be considered for growing solid nodules that are benign on repeat cytology if they are large $(>4 \mathrm{~cm})$, causing compressive or structural symptoms, or based upon clinical concern (21.27). There are four pathological types of thyroid carcinoma, and their treatment and prognosis are different based on the pathological types of thyroid cancer. Papillary and follicular thyroid cancers have a favorable prognosis, with mortality rates of $1 \%$ to $2 \%$ at 20 years for Papillary thyroid cancer (PTC)(28) and $10 \%$ to $20 \%$ at 20 years for follicular thyroid cancer(29). However, patients with medullary thyroid carcinoma have a mortality rate of $25 \%$ to $50 \%$ at 10 years, and most patients with poorly differentiated and Anaplastic thyroid cancer die within one year after diagnosis (5-year mortality, 90\%)(29.30). Papillary thyroid cancer is generally perceived as low-risk thyroid cancer(29) and is not associated with well-recognized predictors of mortality(31.32). With the popularity of high-resolution thyroid ultrasound, the incidence of thyroid nodules has gradually increased(18.29), which is attributed to the increase in papillary thyroid cancer or micropapillary thyroid cancer, and more than $50 \%$ of them are labeled as low-risk thyroid cancer, It may not have any symptoms or affect the life span of the patient (33-35). For micropapillary thyroid cancer, we can consider active surveillance regularly(1.36.37). Generally speaking, the 
scope of surgery for thyroid cancer was determined by the initial clinical characteristics of thyroid nodules, the experience and preference of the surgeon, and the preference of the patient. The American Thyroid Association (ATA) guidelines recommended thyroid lobectomy for low-risk thyroid nodules, and bilateral thyroidectomy (including total thyroidectomy and subtotal thyroidectomy) or thyroid lobectomy for intermediaterisk thyroid nodules(1). many studies have demonstrated that overall survival and disease-free survival are not negatively impacted by lobectomy compared with thyroidectomy (38-44).

The increase in the incidence of thyroid nodules can be seen worldwide(45). In the US, a retrospective population-based evaluation of patients with thyroid cancer found that the incidence increased from 3.6/100000 in 1973 to 8.7/100000 in 2002, a 2.4-fold increase(46); Similarly, we saw that in South Korea between 1993 and 2011, thyroid cancer increased 15 times (47.48). However, the mortality rate of thyroid cancer remained stable or even declined(46-51). At the same time, we have also noticed that the number of thyroid surgeries increased dramatically. Two studies have shown a 2-4 times increase in the number of thyroid surgeries(49.50). Another study showed that between 2006 and 2011 , the number of thyroid surgeries in the United States increased from 99,613 to 130,216 per year, with an average annual growth rate of $12 \%$ (52). This evidence also indirectly indicated that more aggressive treatment strategies were adopted for thyroid nodules in clinical practice. Because all the b-side thyroid glands were thyroid cancers in the experimental group, unilateral lobectomy was performed in all the b-side thyroid glands in the experimental group. In the pathological types of b-side thyroid nodules in the experimental group 1 and 2 , the proportion of papillary thyroid carcinoma was $98.46 \%$ and $94.74 \%$, respectively. Moreover, micropapillary thyroid carcinoma reached $47.69 \%$ and $36.84 \%$ respectively. We have known that papillary thyroid cancer, especially Papillary thyroid microcarcinoma, is an indolent tumor, most of which may not have an impact on the lifespan of patients. In our study, we found that almost all the b-side thyroid nodules in the experimental group were thyroid papillary carcinoma, and the a-side thyroid nodules in the experimental group were benign, but there were $46.15 \%$ and $85.71 \%$ lobectomy in the a-side of the experimental group 1 and 2, respectively. The a-side thyroid nodules were malignant, we saw a higher proportion, up to $84.62 \%$ and $96.55 \%$ in the experimental group 1 and 2, respectively. There were not many cases in our study, however, it reflected the current status of more aggressive treatment strategies for thyroid nodules to some extent. This was reflected not only in the substantial increase in the number of thyroid nodule surgeries but also in more thorough surgical procedures, which tend to subtotal thyroidectomy or total thyroidectomy. Many studies have confirmed that more resources were used for the diagnosis, treatment, and follow-up of those thyroid cancers, which may not affect the life of the patient or even have no symptoms(33.34). A large observational study based on the SEER database found that after controlling tumor size, for those patients with low-risk tumors, aggressive surgical treatment has no benefit in survival(41). Several studies have indirectly demonstrated the current status of overtreatment of thyroid nodules(20.33.34.50.52.53).

When it comes to thyroid surgery, postoperative complications are an inevitable issue. Common complications after thyroid surgery include dyspnea, nerve damage (including superior laryngeal nerve injury, and recurrent laryngeal nerve injury), hypoparathyroidism(54.55). One study showed that the risk of total thyroidectomy included recurrent laryngeal nerve injury (2.5\%, rarely on both sides), hypocalcemia (8.1\%), and bleeding (56). Does more aggressive surgery for thyroid nodules increase the risk of postoperative complications? A study showed that different thyroid surgical procedures and the incidence of postoperative hypocalcemia were not statistically significant(57). However, Another study showed that there was a significant difference in postoperative complications between total thyroidectomy and partial thyroidectomy. The incidence of permanent nerve injury was $7.0 \%$ vs $1.3 \%(p<0.005)$, temporary nerve injury $8.6 \%$ vs $2.2 \%$ ( $p<0.005$ ), and postoperative transient hypoparathyroidism $18.0 \%$ vs $2.1 \%(p<0.005)(38)$. moreover, Thyroid lobectomy can provide histological diagnosis and tumor removal with a lower risk of complications(18). Therefore, the current more aggressive treatment strategy for thyroid nodules may not be a good choice for patients and society.

we can take a more conservative treatment for the low-to medium-risk thyroid gland, which can retain enough thyroid tissue to meet normal physiological needs without affecting the prognosis of the patient while reducing the possibility of postoperative complications. Moreover, at present, patients with low-to medium-risk thyroid nodules are the most common patients in clinical practice, accounting for the vast majority of all patients. Nowadays, the increasing burden of health care in various countries, especially in the face of coronavirus this year, makes their medical funds tighter. For thyroid nodules, we should do more research on the treatment and benefits (including patients and society) to reduce the waste of medical resources and the risk of complications after thyroid surgery.

Although preliminary conclusions are drawn based on our trial data, there are still many limitations to be improved. Our study is a retrospective cohort study and has its limitations. There may be selective errors in the experimental group and the control group cases. But this also reflected the current status of surgical treatment of thyroid nodules. The study is a single-center case study with insufficient evidence and needs to be conducted in a multi-center and larger population. Our study almost only studied the effect of papillary thyroid carcinoma on the malignant risk of contralateral thyroid nodules, and other types of thyroid pathology can also be considered in the future. Our study did not conduct prospective studies on postoperative complications of thyroid surgery. We hope that there will be more studies on the correlation between different thyroid surgical procedures and complications in the future. Although many studies have indirectly confirmed that the current more aggressive thyroid treatment strategy leads to a large waste of medical resources, direct evidence are still lacking. Therefore, the treatment strategy of thyroid nodules still needs further research, so that it can find a balance point in terms of treatment effect, risk of postoperative complications, and 
economy, so that clinically significant thyroid nodules can be treated timely and appropriately, and It will not increase the burden on patients, including physical, mental, and economic aspects, and cause waste of medical resources.

Finally, the issue of fine-needle aspiration biopsy(FNAB) of thyroid nodules is specifically explained. Many thyroid treatment guidelines recommend FNAB before surgery, but FNAB has a high proportion of insufficient biopsy specimens and indeterminate pathological results. For those patients with insufficient biopsy specimens or indeterminate pathological results, FNAB may need to be performed again. However, some patients may not have clear pathological results after repeated FNAB. In our study, surgeons advised all patients with thyroid nodules to perform FNAB, but fully informed them of the pros and cons, and almost all patients refused to perform FNAB. Because of the improvement of surgical techniques, anesthesia, and nursing care, the length of hospital stay has been shortened, which is another reason.

\section{Conclusions}

According to our current data, there is no evidence that bilateral thyroid nodules affect each other in terms of malignant risk, that is, in bilateral thyroid nodules, unilateral thyroid cancer does not change the malignant risk of contralateral thyroid nodules.

\section{Declarations}

Ethics approval and consent to participate:

The study was approved by the Ethics Committee of the Fourth Affiliated Hospital of China Medical University, and its number is EC-2020-KS021. The informed consent of patients was obtained in this study.

Consent for publication: Not applicable

Availability of data and materials囚the data used during the current research are available from the corresponding author on reasonable request.

Competing interests: The authors declare that they have no competing interests.

Funding

This research did not receive any specific grant from funding agencies in the public, commercial, or not-for-profit sectors.

Authors' contributions

$\mathrm{HL}$ participated in research design, literature review, data collection and statistical analysis, discussion, and article writing. JJ and QC participated in data collection, analysis and discussion. ZL participated in research design, analysis, discussion, and review. All authors read and approved the final manuscript.

Acknowledgements: not applicable.

\section{References}

1. Haugen BR. Alexander EK, Bible KC, et al 2015 American Thyroid Association Management Guidelines for Adult Patients with Thyroid Nodules and Differentiated Thyroid Cancer: The American Thyroid Association Guidelines Task Force on Thyroid Nodules and Differentiated Thyroid Cancer. Thyroid. 2016;26(1):1-133. doi:10.1089/thy.2015.0020.

2. Guth S, Theune U, Aberle J, Galach A, Bamberger CM. Very high prevalence of thyroid nodules detected by high frequency (13 MHz) ultrasound examination. Eur J Clin Invest. 2009;39(8):699-706. doi:10.1111/j.1365-2362.2009.02162.x.

3. Durante C, Grani G, Lamartina L, Filetti S, Mandel SJ, Cooper DS. The Diagnosis and Management of Thyroid Nodules: A Review [published correction appears in JAMA. 2018 Apr 17;319(15):1622]. JAMA. 2018;319(9):914-924. doi:10.1001/jama.2018.0898.

4. Russ G, Leboulleux S, Leenhardt L, Hegedüs L. Thyroid incidentalomas: epidemiology, risk stratification with ultrasound and workup. Eur Thyroid J. 2014;3(3):154-63. doi:10.1159/000365289.

5. Perros P, Boelaert K, Colley S, et al. Guidelines for the management of thyroid cancer. Clin Endocrinol (Oxf). 2014;81(Suppl 1):1-122. doi:10.1111/cen.12515.

6. Gharib H, Papini E, Paschke R, et al. American Association of Clinical Endocrinologists, Associazione Medici Endocrinologi, and European Thyroid Association medical guidelines for clinical practice for the diagnosis and management of thyroid nodules: Executive Summary of recommendations. J Endocrinol Invest. 2010;33(5):287-91. doi:10.1007/BF03346587.

7. Elsayed AA, Murdoch C, Murray S, Bashir K. Can thyroid surgery be decided based on ultrasonographic findings, irrespective of cytopathological findings? Five-year retrospective study in a district general hospital. Clin Radiol. 2017;72(2):170-4.

Page 6/11 
doi:10.1016/j.crad.2016.10.001.

8. Farrá JC, Picado O, Liu S, et al. Clinically significant cancer rates in incidentally discovered thyroid nodules by routine imaging. J Surg Res. 2017;219:341-6. doi:10.1016/j.jss.2017.06.050.

9. Paschou SA, Vryonidou A, Goulis DG. Thyroid nodules: A guide to assessment, treatment and follow-up. Maturitas. 2017;96:1-9. doi:10.1016/j.maturitas.2016.11.002.

10. Mazeh H, Beglaibter N, Prus D, Ariel I, Freund HR. Cytohistologic correlation of thyroid nodules. Am J Surg. 2007;194(2):161-3. doi:10.1016/j.amjsurg.2006.10.025.

11. Bomeli SR, LeBeau SO, Ferris RL. Evaluation of a thyroid nodule. Otolaryngol Clin North Am. 2010;43(2):229-vii. doi:10.1016/j.otc.2010.01.002.

12. Shrestha D, Shrestha S. The incidence of thyroid carcinoma in multinodular goiter: a retrospective study. JCMS Nepal. 2014;10:18-22. doi:10.3126/jcmsn.v10i4.12974.

13. Steele SR, Martin MJ, Mullenix PS, Azarow KS, Andersen CA. The significance of incidental thyroid abnormalities identified during carotid duplex ultrasonography. Arch Surg. 2005;140(10):981-5. doi:10.1001/archsurg.140.10.981.

14. Papini E, Guglielmi R, Bianchini A, et al. Risk of malignancy in nonpalpable thyroid nodules: predictive value of ultrasound and color-Doppler features. J Clin Endocrinol Metab. 2002;87(5):1941-6. doi:10.1210/jcem.87.5.8504.

15. Aspinall SR, Ong SG, Wilson MS, Lennard TW. How shall we manage the incidentally found thyroid nodule? Surgeon. 2013;11(2):96-104. doi:10.1016/j.surge.2012.11.004.

16. Bessey LJ, Lai NB, Coorough NE, Chen H, Sippel RS. The incidence of thyroid cancer by fine needle aspiration varies by age and gender. J Surg Res. 2013;184(2):761-5. doi:10.1016/j.jss.2013.03.086.

17. Rahib L, Smith BD, Aizenberg R, Rosenzweig AB, Fleshman JM, Matrisian LM. Projecting cancer incidence and deaths to 2030: the unexpected burden of thyroid, liver, and pancreas cancers in the United States [published correction appears in Cancer Res. 2014 Jul 15;74(14):4006]. Cancer Res. 2014;74(11):2913-2921. doi:10.1158/0008-5472.CAN-14-0155.

18. Filetti S, Durante C, Torlontano M. Nonsurgical approaches to the management of thyroid nodules. Nat Clin Pract Endocrinol Metab. 2006;2(7):384-94. doi:10.1038/ncpendmet0215.

19. Tessler FN, Middleton WD, Grant EG, Hoang JK, Berland LL, Teefey SA, Cronan JJ, Beland MD, Desser TS, Frates MC, Hammers LW, Hamper UM, Langer JE, Reading CC, Scoutt LM, Stavros AT. ACR Thyroid Imaging, Reporting and Data System (TI-RADS): White Paper of the ACR TIRADS Committee. J Am Coll Radiol. 2017 May;14(5):587-95. doi: 10.1016/j.jacr.2017.01.046. Epub 2017 Apr 2. PMID: 28372962.

20. Brito JP, Yarur AJ, Prokop LJ, Mclver B, Murad MH, Montori VM. Prevalence of thyroid cancer in multinodular goiter versus single nodule: a systematic review and meta-analysis. Thyroid. 2013;23:449-55. doi:10.1089/thy.2012.0156.

21. Chen AY, Bernet VJ, Carty SE, et al. American Thyroid Association statement on optimal surgical management of goiter. Thyroid. 2014;24(2):181-9. doi:10.1089/thy.2013.0291.

22. BurmanKD WL. CLINICAL PRACTICE. Thyroid Nodules. N EngIJ Med. 2015;373:2347-56. doi:10.1056/NEJMcp1415786.

23. Smith-Bindman R, Lebda P, Feldstein VA, et al. Risk of thyroid cancer based on thyroid ultrasound imaging characteristics: results of a population-based study. JAMA Intern Med. 2013;173(19):1788-96. doi:10.1001/jamainternmed.2013.9245.

24. Ito $\mathrm{Y}$, Uruno T, Nakano K, et al. An observation trial without surgical treatment in patients with papillary microcarcinoma of the thyroid. Thyroid. 2003;13(4):381-7. doi:10.1089/105072503321669875.

25. Davies L, Welch HG. Current thyroid cancer trends in the United States. JAMA Otolaryngol Head Neck Surg. 2014;140(4):317-22. doi:10.1001/jamaoto.2014.1.

26. Roti E, degli Uberti EC, Bondanelli M, Braverman LE. Thyroid papillary microcarcinoma: a descriptive and meta-analysis study. Eur J Endocrinol. 2008;159(6):659-73. doi:10.1530/EJE-07-0896.

27. Shin JJ, Caragacianu D, Randolph GW. Impact of thyroid nodule size on prevalence and post-test probability of malignancy: a systematic review. Laryngoscope. 2015;125(1):263-72. doi:10.1002/lary.24784.

28. Hay ID, Bergstralh EJ, Goellner JR, Ebersold JR, Grant CS. Predicting outcome in papillary thyroid carcinoma: development of a reliable prognostic scoring system in a cohort of 1779 patients surgically treated at one institution during 1940 through 1989 . Surgery. 1993;114(6):1050-8.

29. American Thyroid Association (ATA) Guidelines Taskforce on Thyroid Nodules and Differentiated Thyroid Cancer. Cooper DS, Doherty GM, et al. Revised American Thyroid Association management guidelines for patients with thyroid nodules and differentiated thyroid cancer [published correction appears in Thyroid. 2010 Aug;20(8):942. Hauger, Bryan R [corrected to Haugen, Bryan R]] [published correction appears in Thyroid. 2010 Jun;20(6):674-5]. Thyroid. 2009;19(11):1167-1214. doi:10.1089/thy.2009.0110.

30. Mclver B, Hay ID, Giuffrida DF, et al. Anaplastic thyroid carcinoma: a 50-year experience at a single institution. Surgery. 2001;130(6):102834. doi:10.1067/msy.2001.118266.

Page $7 / 11$ 
31. Toubeau M, Touzery C, Arveux P, et al. Predictive value for disease progression of serum thyroglobulin levels measured in the postoperative period and after (131)I ablation therapy in patients with differentiated thyroid cancer. J Nucl Med. 2004;45(6):988-94.

32. Rouxel A, Hejblum G, Bernier MO, et al. Prognostic factors associated with the survival of patients developing loco-regional recurrences of differentiated thyroid carcinomas. J Clin Endocrinol Metab. 2004;89(11):5362-8. doi:10.1210/jc.2003-032004.

33. Welch HG, Black WC. Overdiagnosis in cancer. J Natl Cancer Inst. 2010;102(9):605-13. doi:10.1093/jnci/djq099.

34. Morris LG, Sikora AG, Tosteson TD, Davies L. The increasing incidence of thyroid cancer: the influence of access to care. Thyroid. 2013;23(7):885-91. doi:10.1089/thy.2013.0045.

35. Malone MK, Zagzag J, Ogilvie JB, Patel KN, Heller KS. Thyroid cancers detected by imaging are not necessarily small or early stage. Thyroid. 2014;24(2):314-8. doi:10.1089/thy.2012.0651.

36. Brito JP, Ito Y, Miyauchi A, Tuttle RM. A Clinical Framework to Facilitate Risk Stratification When Considering an Active Surveillance Alternative to Immediate Biopsy and Surgery in Papillary Microcarcinoma. Thyroid. 2016;26(1):144-9. doi:10.1089/thy.2015.0178.

37. Ito $\mathrm{Y}$, Miyauchi A, Inoue $\mathrm{H}$, et al. An observational trial for papillary thyroid microcarcinoma in Japanese patients. World $\mathrm{J}$ Surg. 2010;34(1):28-35. doi:10.1007/s00268-009-0303-0.

38. Osmólski A, Frenkiel Z, Osmólski R. Chirurgiczne leczenie chorób tarczycy-powikłania pooperacyjne [Complications in surgical treatment of thyroid diseases]. Otolaryngol Pol. 2006;60(2):165-70.

39. Matsuzu K, Sugino K, Masudo K, et al. Thyroid lobectomy for papillary thyroid cancer: long-term follow-up study of 1,088 cases. World J Surg. 2014;38(1):68-79. doi:10.1007/s00268-013-2224-1.

40. Barney BM, Hitchcock YJ, Sharma P, Shrieve DC, Tward JD. Overall and cause-specific survival for patients undergoing lobectomy, near-total, or total thyroidectomy for differentiated thyroid cancer. Head Neck. 2011;33(5):645-9. doi:10.1002/hed.21504.

41. Mendelsohn AH, Elashoff DA, Abemayor E, St John MA. Surgery for papillary thyroid carcinoma: is lobectomy enough? Arch Otolaryngol Head Neck Surg. 2010;136(11):1055-61. doi:10.1001/archoto.2010.181.

42. Haigh PI, Urbach DR, Rotstein LE. Extent of thyroidectomy is not a major determinant of survival in low- or high-risk papillary thyroid cancer. Ann Surg Oncol. 2005;12(1):81-9. doi:10.1007/s10434-004-1165-1.

43. Nixon IJ, Ganly I, Patel SG, et al. Thyroid lobectomy for treatment of well differentiated intrathyroid malignancy. Surgery. 2012;151(4):5719. doi:10.1016/j.surg.2011.08.016.

44. Bilimoria KY, Bentrem DJ, Ko CY, Stewart AK, Winchester DP, Talamonti MS. Sturgeon C 2007 Extent of surgery affects survival for papillary thyroid cancer. Ann Surg 246:375-381.

45. urado MP,EB, Shin HR, Storm H, Ferlay J, Heanue M, Boyle P Cancer Incidence in Five Continents. Vol. IX. IARC Scientific Publications No. 160; Lyon: IARC: 2007.

46. Davies L, Welch HG. Increasing incidence of thyroid cancer in the United States, 1973-2002. JAMA 2006;295:2164-7. doi:10.1001/ jama.295.18.2164.

47. Ahn HS, Kim HJ, Welch HG. Korea's thyroid-cancer "epidemic"--screening and overdiagnosis. N Engl J Med. 2014;371:1765-7. doi:10.1056/NEJMp1409841.

48. Ahn HS, Kim HJ, Kim KH, et al. Thyroid Cancer Screening in South Korea Increases Detection of Papillary Cancers with No Impact on Other Subtypes or Thyroid Cancer Mortality. Thyroid. 2016;26:1535-40. doi:10.1089/thy.2016.0075.

49. Du L, Wang Y, Sun X, et al. Thyroid cancer: trends in incidence, mortality and clinical-pathological patterns in Zhejiang Province, Southeast China. BMC Cancer. 2018;18(1):291. Published 2018 Mar 15. doi:10.1186/s12885-018-4081-7.

50. Jegerlehner S, Bulliard JL, Aujesky D, et al. Overdiagnosis and overtreatment of thyroid cancer: A population-based temporal trend study. PLoS One. 2017;12(6):e0179387. doi:10.1371/journal.pone.0179387. Published 2017 Jun 14.

51. Kilfoy BA, Zheng T, Holford TR, et al. International patterns and trends in thyroid cancer incidence, 1973-2002. Cancer Causes Control. 2009;20(5):525-31. doi:10.1007/s10552-008-9260-4.

52. Sosa JA, Hanna JW, Robinson KA, Lanman RB. Increases in thyroid nodule fine-needle aspirations, operations, and diagnoses of thyroid cancer in the United States. Surgery. 2013; 154(6):1420-1426. discussion 1426-1427, doi:10.1016/j.surg.2013.07.006.

53. Janovsky CCPS, Bittencourt MS, Novais MAP, Maciel RMB, Biscolla RPM, Zucchi P. Thyroid cancer burden and economic impact on the Brazilian public health system. Arch Endocrinol Metab. 2018;62(5):537-44. doi:10.20945/2359-3997000000074.

54. Karamanakos SN, Markou KB, Panagopoulos K, et al. Complications and risk factors related to the extent of surgery in thyroidectomy. Results from 2,043 procedures. Hormones (Athens). 2010;9(4):318-25. doi:10.14310/horm.2002.1283.

55. Abboud B, Sargi Z, Akkam M, Sleilaty F. Risk factors for postthyroidectomy hypocalcemia. J Am Coll Surg. 2002;195(4):456-61. doi:10.1016/s1072-7515(02)01310-8.

56. Randolph GW, Shin JJ, Grillo HC, et al. The surgical management of goiter: Part II. Surgical treatment and results. Laryngoscope. 2011;121(1):68-76. doi:10.1002/lary.21091. 
57. Shiryazdi SM, Kargar S, Afkhami-Ardekani M, Neamatzadeh H. Risk of postoperative hypocalcemia in patients underwent total thyroidectomy, subtotal thyroidectomy and lobectomy surgeries. Acta Med Iran. 2014;52(3):206-9.

\section{Tables}

Table 1

Statistical analysis of demographic characteristics of the experimental group and the control group

\begin{tabular}{|c|c|c|c|c|c|c|}
\hline & \multicolumn{2}{|l|}{ Gender } & \multirow[t]{2}{*}{ P-value } & \multicolumn{2}{|l|}{ Age } & \multirow[t]{2}{*}{ P-value } \\
\hline & Male & Female & & Mean & $95 \% \mathrm{Cl}$ & \\
\hline Experimental group 1 & $10(15.38 \%)$ & $55(84.62 \%)$ & \multirow[t]{2}{*}{0.680} & 50.11 & $(39.87,60.36)$ & \multirow[t]{2}{*}{0.993} \\
\hline Control group 1 & $1(7.14 \%)$ & $14(92.86 \%)$ & & 50.13 & $(40.65,60.08)$ & \\
\hline Experimental group 2 & $0(0.00 \%)$ & $15(100 \%)$ & \multirow[t]{2}{*}{0.016} & 53.21 & $(39.98,66.44)$ & \multirow[t]{2}{*}{0.037} \\
\hline Control group 2 & $19(45.24 \%)$ & $23(54.76 \%)$ & & 46.76 & $(37.33,56.19)$ & \\
\hline
\end{tabular}

Table 2

statistical results of pathology and surgical procedures of thyroid nodules

\begin{tabular}{|c|c|c|c|c|c|c|c|c|c|}
\hline & \multicolumn{2}{|c|}{$\begin{array}{l}\text { Thyroid nodules } \\
\text { Pathology }\end{array}$} & \multirow[t]{2}{*}{$\begin{array}{l}\mathrm{P}- \\
\text { value }\end{array}$} & \multicolumn{2}{|c|}{$\begin{array}{l}\text { Pathological types of thyroid } \\
\text { cancer }\end{array}$} & \multirow[t]{2}{*}{$\begin{array}{l}\mathrm{P}- \\
\text { value }\end{array}$} & \multicolumn{2}{|c|}{ Thyroid surgical procedure* } & \multirow[t]{2}{*}{$\begin{array}{l}\mathrm{P} \text { - } \\
\text { value }\end{array}$} \\
\hline & Benign & Malignant & & $\begin{array}{l}\text { Micropapillary } \\
\text { thyroid cancer }\end{array}$ & $\begin{array}{l}\text { Papillary } \\
\text { Thyroid } \\
\text { Cancer }\end{array}$ & & Lobectomy & $\begin{array}{l}\text { Unilateral } \\
\text { partial } \\
\text { thyroidectomy }\end{array}$ & \\
\hline $\begin{array}{l}\text { Experimental group } \\
1(\%)\end{array}$ & $52(80 \%)$ & $13(20 \%)$ & 0.724 & $8(61.54 \%)$ & $5(38.46 \%)$ & 0.200 & $24(46.15 \%)$ & $28(53.85 \%)$ & 0.131 \\
\hline Control group 1(\%) & $13(65 \%)$ & $2(35 \%)$ & & $0(0.00 \%)$ & $2(100.00 \%)$ & & $3(23.08 \%)$ & $10(77.92 \%)$ & \\
\hline $\begin{array}{l}\text { Experimental group } \\
2(\%)\end{array}$ & $7(36.84 \%)$ & $12(63.16 \%)$ & 0.297 & $10(83.33 \%)$ & $2(16.67 \%)$ & 0.620 & $6(85.71 \%)$ & $1(14.29 \%)$ & 0.001 \\
\hline Control group 2(\%) & $9(23.68 \%)$ & $29(76.32 \%)$ & & $26(89.66 \%)$ & $3(10.34 \%)$ & & $0(0.00 \%)$ & $9(100.00 \%)$ & \\
\hline
\end{tabular}

Table 3

distribution of surgical procedures for malignant thyroid nodules*

\begin{tabular}{|lll|}
\hline & \multicolumn{2}{c|}{ Thyroid surgical procedure* } \\
\hline Experimental group $1(\%)$ & Lobectomy & Unilateral partial thyroidectomy \\
\hline Control group $1(\%)$ & $11(84.62 \%)$ & $2(15.38 \%)$ \\
\hline Experimental group $2(\%)$ & $2(100.00 \%)$ & $0(0.00 \%)$ \\
\hline Control group $2(\%)$ & $12(100 \%)$ & $0(0.00 \%)$ \\
\hline $\begin{array}{l}* \\
\text { group above discussion was the surgical procedures of malignant thyroid nodules on the a-side of the experimental group and the control }\end{array}$ \\
\hline
\end{tabular}


Pathological types of b-side thyroid cancer in the experimental group

\begin{tabular}{|c|c|c|c|c|c|}
\hline & \multicolumn{2}{|c|}{ Papillary Thyroid Cancer } & \multirow{2}{*}{$\begin{array}{l}\text { Medullary Thyroid } \\
\text { Cancer }\end{array}$} & \multirow{2}{*}{$\begin{array}{l}\text { Follicular thyroid } \\
\text { carcinoma }\end{array}$} & \multirow{2}{*}{$\begin{array}{l}\text { Anaplastic thyroic } \\
\text { carcinoma }\end{array}$} \\
\hline & Yes* & no & & & \\
\hline $\begin{array}{l}\text { Experimental group } \\
1(\%)\end{array}$ & $31(47.69 \%)$ & $33(50.77 \%)$ & $1(1.54 \%)$ & $0(0 \%)$ & $0(0 \%)$ \\
\hline $\begin{array}{l}\text { Experimental group } \\
2(\%)\end{array}$ & $7(36.84 \%)$ & $11(57.90 \%)$ & $0(0 \%)$ & $0(0 \%)$ & $1(5.26 \%)$ \\
\hline
\end{tabular}

\section{Figures}

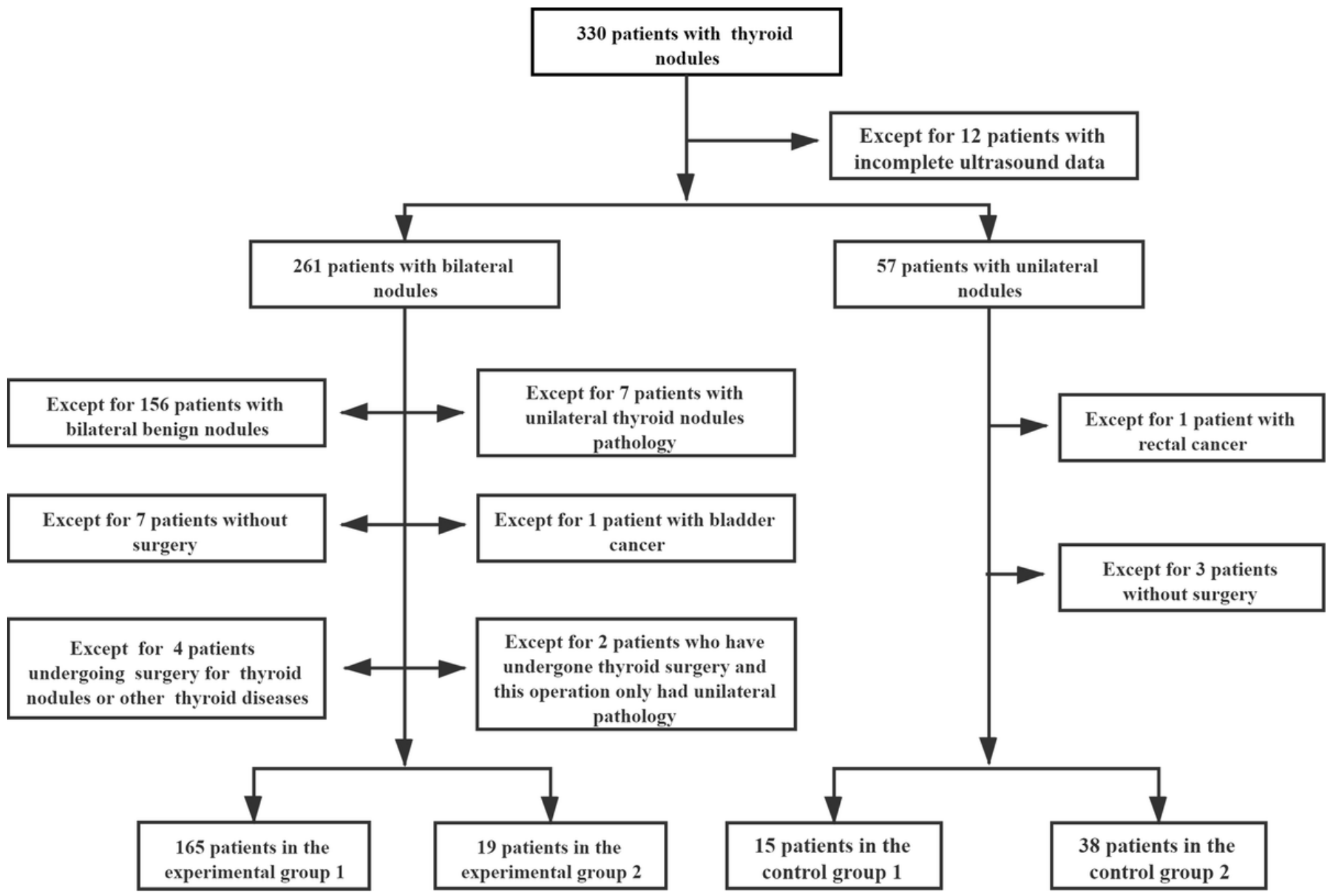

Figure 1

Process of cases collection and grouping 


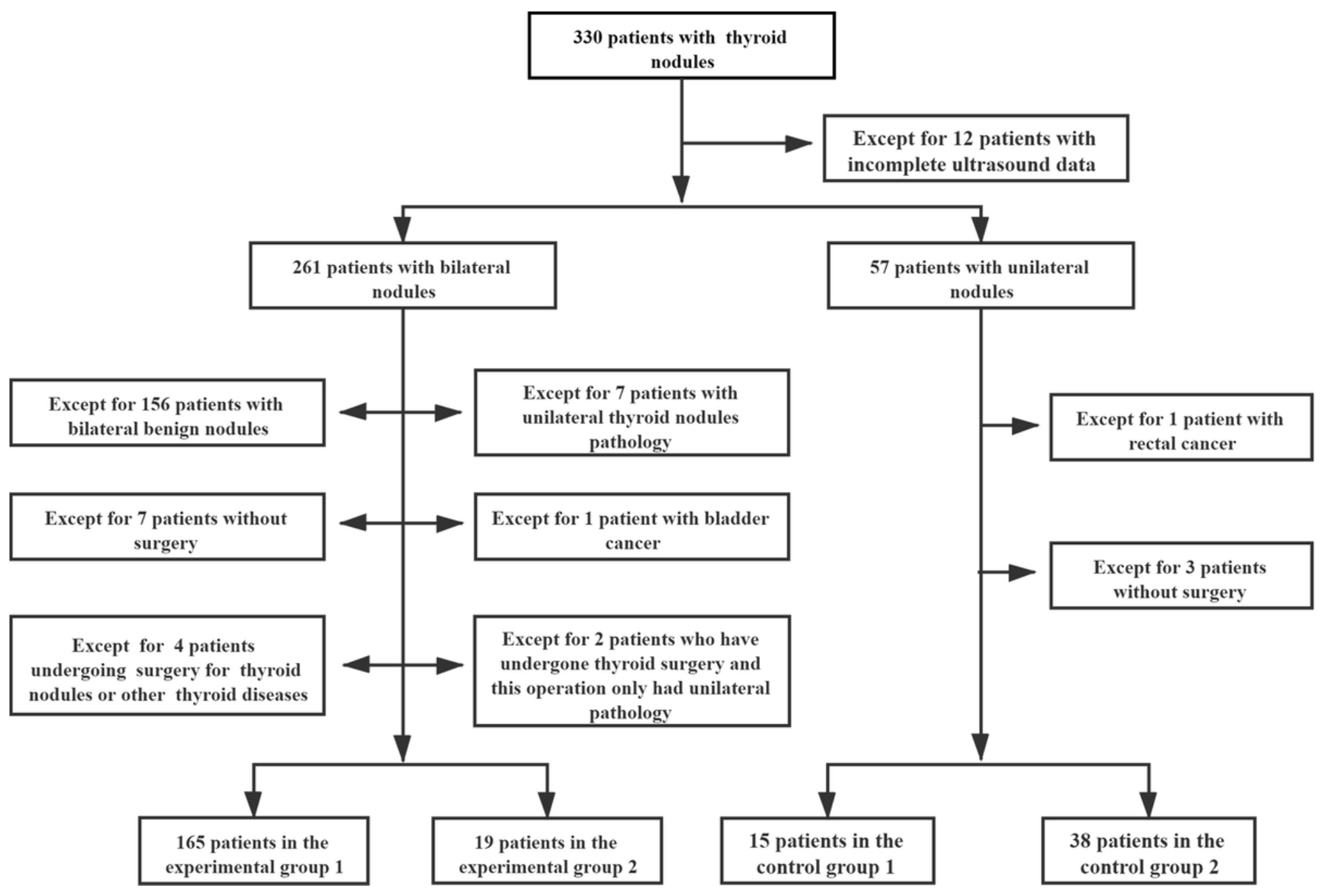

Figure 1

Process of cases collection and grouping 